\title{
Singuagens
}

\section{MACHISMO E EROTISMO NO CONTO BURITI, DE GUIMARÃES ROSA}

\author{
Joselaine Brondani Medeiros Cobo (UFSM)
}

\begin{abstract}
RESUMO: O livro Corpo de baile, de Guimarães Rosa, foi publicado em 1956 e contém sete narrativas, sendo a última intitulada Buriti. Nela há a história de Miguel, adulto, formado em medicina veterinária, que, depois de morar muitos anos na cidade, retorna à fazenda "Buriti Bom" para trabalhar. O dono da fazenda era Liodoro, um homem rico, machista e dominador. Ele era pai de Glória e sogro de Lalinha, moça citadina, que se vê prisioneira do sertão. A sexualidade das duas se aguça na medida em que elas se encontram com Miguel nos campos rodeados de buritizais. O sertão faz desabrochar os desejos mais ocultos das personagens. O Buriti se torna símbolo do desejo e do amor.
\end{abstract}

PALAVRAS-CHAVE: Guimarães Rosa. Erotismo. Desejo. Transgressão.

ABSTRACT: The book Corpo de baile, by Guimarães Rosa, was published in 1956 and contains seven narratives, and the last one is entitled "Buriti". In it, there is the story of Miguel, adult, graduated in veterinary science, who, after living many years in the city, comes back to the farm "Buriti Bom" in order to work. The farm's owner was Liodoro, a rich man, male chauvinist and dominant. He was Glória's father and Lalinha's father-in-law, who is a civic young woman that feels a hinterland's prisoner. The sexuality of the two young women gets stronger as they meet Miguel in the fields surrounded by buritizais. The hinterland makes to blossom the most occult desires of the characters. Buriti becomes the symbol of desire and love.

KEYWORDS: Guimarães Rosa. Eroticism. Desire. Transgression.

If

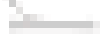

Objetiva-se, nesse trabalho, analisar o conto Buriti, de Guimarães Rosa, que encerra a obra Corpo de baile, ressaltando o erotismo e o patriarcalismo presente no homem e no sertão. A natureza exerce papel decisivo com relação ao erotismo: pecado, transgressão, amor e sexo acabam entrelaçados à natureza, com sua exuberância. Buriti Bom, a fazenda e o falo intensificam o patriarcalismo na figura do poderoso fazendeiro Liodoro. Vale destacar que Buriti, na língua indígena, significa "a árvore que emite líquidos", "a arvore da vida", tendo fortemente a conotação sexual, bem como elemento que dá continuação à vida. Buriti como metáfora do homem, a água, onde ela cresce, como elemento feminino.

O conto pode ser dividido em duas partes: a primeira relembrada por Miguel, com a ajuda de Nhô Gualberto. O moço citadino rememora sua primeira passagem, após a infância, pelos campos da região mineira. Nesse período, ele conheceu Glória, moça fogosa e linda, filha do fazendeiro Liodoro. Ela despertou interesse e paixão em Miguel, porém ele teve que partir, quase de forma clandestina, sem firmar compromisso com a moça. Na segunda parte da narrativa, ocorre o desvelamento de Leandra, Lala ou Lalinha, nora de Iô Liodoro, mostrando Linguagens \& Cidadania, v. 19, jan./dez., 2017. 


\section{S Linguagens}

seus anseios e desejos reprimidos. Há, desse modo, dois fios condutores: um constrói o romance de Miguel, e outro representa o romance de Lalinha, sendo este maior e mais intenso, visto que trata do desabrochar para o amor e para o sexo nas personagens femininas Glória e Lala.

A narrativa de "Buriti" é bastante complexa, por serem apresentadas as características de várias personagens, que falam e tecem os fios da rememoração de Miguel: há a palavra do próprio Miguel, de Maria da Glória, de Lalinha, de Chefe Zequiel, de Nhô Gaspar e Iô Liodoro. Miguel fia e desfia suas reminiscências, como Penélope, esposa de Ulisses, que costurava a mortalha para Laertes, seu sogro, durante o dia e descosturava durante a noite. Por meio da técnica do avanço e do recuo temporal, o narrador vai contando, em ziguezague, a vida no Buriti-Bom, adentrando na mente das personagens e revelando os seus desejos reprimidos e sentimentos interiores.

A narrativa parte em flashback, através das lembranças de Miguel, que, como veterinário, visitou as fazendas de Nhô Gualberto e Iô Liodoro alguns anos atrás. O jovem que nascera no interior, mas crescera na cidade, defronta-se com o seu passado e com o seu "eu" de agora, tenta, então, reconstruir a sua identidade. Dá-se uma espécie de enfrentamento: Miguel é meio filho do sertão, já que cresceu no Mutúm, e meio filho da cidade, local onde se formou e se transformou em representante do saber intelectual. Miguilim, o menino solitário e inseguro, transformou-se em Miguel, homem perfeccionista e dotado de conhecimentos.

Miguel vem às fazendas Grumixã, de Nhô Gualberto, e Buriti Bom, de Iô Liodoro, exercer o seu trabalho: vacinar e cuidar do gado, o que não esperava era conhecer e se envolver com duas moças: Maria da Glória e Lalinha. Durante os passeios pelos campos, junto com Gualberto, viu de perto o Buriti-Grande, árvore ancestral, que o acompanharia ao longo da sua história e se converteria em uma personagem ao longo do texto. Ele partiu e novamente retornou, num movimento de ida e volta, como sua vida, o seu recordar da infância à maturidade. Nesse intervalo, ocorrem algumas mudanças como a morte de Maria Behú, após longa enfermidade, e a melhora de Chefe Zequiel, que, tomou umas pílulas salvadoras, trazidas na ocasião do enterro de Maria Behú, e civilizara, tanto que "não envigia a noite mais, dorme seu sono frouxo" (ROSA, 2001, p. 315). O buriti, nesse ínterim, continuava, ano após ano, o ser supremo, dominando a região do interior mineiro, descrita por Rosa. 


\section{Linguagens}

O buriti é uma palmeira nativa do Brasil, encontrável desde o cerrado até a floresta amazônica, própria de terrenos pantanosos. Nas regiões onde aparece, o buriti tem grande importância para as populações locais, uma vez que os frutos e as folhas são utilizados e comercializados, servindo não só como alimento, mas também como fonte de renda. Essas palmeiras conferem colorido especial à obra de Guimarães Rosa: acompanham a vida de Miguilim, na infância no Mutúm, retratando a figura de um pai rude e violento e de uma mãe suave e submissa, que, de tanto sofrer, acaba se envolvendo e se apaixonando por outro homem; de Manuelzão, homem feito, já de certa idade, frustrado com a vida, sozinho e infeliz; e de Miguel, adulto, que volta da cidade, estudado, e chega ao Buriti Bom, deparandose com duas mulheres diferentes, porém encantadoras: Maria da Glória e dona Lalinha.

Miguilim-Miguel faz a viagem, comum nas narrativas de Rosa, deixando em suspenso a promessa do amor por Maria da Glória, e é esse o motivo patente de seu retorno, O sertão se afigurava para ele como o lugar da falta, símbolo da desagregação familiar. A volta ao Buriti Bom é a possibilidade do resgate e da transformação dos afetos perdidos na infância. Miguel tem a possibilidade de refazer o percurso, de se reencontrar e tentar ser feliz. No final, sente a vida pulsar, quer pedir a Iô Liodoro a mão de Maria da Glória em casamento. Antes, passa no Buriti-Grande, como se fosse um ritual, uma libertação da opressão vivida na infância: "o Buriti-Grande - uma liberdade. Miguel desceu de pensamento. A vida não tem passado. Toda hora o barro se refaz. Deus ensina" (ROSA, 2001, p. 316).

Além disso, o buriti habita o sertão e o sertanejo. A árvore representa o homem ereto pronto para o sexo e para procriação, é a transmutação do homem forte e rígido. É Iô Liodoro, viúvo rico, poderoso, dominador, dono da fazenda Buriti Bom, centro da família, pois, como afirma Machado, "é para ele que tudo converge, é nele que tudo se articula, é dele que se irradiam os acontecimentos, é seu peso de patriarca e proprietário que domina o universo do conto" (MACHADO, 2003, p. 122).

A centralidade ocupada por Liodoro, segundo Machado, está no próprio nome dele: Liodoro, que vem de Heliodoro: o sol, "centro do sistema, em torno do qual gravitam a família e os agregados do Buriti Bom”. (MACHADO, 2003, p. 122). O falo, poderoso é Iô Liodoro, representante da sociedade dominante. Nesse viés, Bordieu (1998), define masculino e feminino através das polaridades alto/baixo, seco/úmido, duro/mole, claro/escuro que, em 


\section{S Linguagens}

linhas gerais, perpetuam a distinção entre o homem dominador e a mulher submissa. O Buriti e Liodoro se transmutam sob o signo do erotismo e masculinidade.

Sua família é composta basicamente por mulheres: as duas filhas, Maria da Glória e Maria Behú, e a nora, dona Lalinha. Os dois filhos homens não moram com ele: Iô Irvino abandonara dona Lalinha e fugira com outra mulher; Iô Ísio, amasiado com uma meretriz, Dijina, vive na fazenda Lapa-Laje, para lá do rio, por sua mulher não ser aceita no seio de uma família tradicional e de bons costumes, como a de Iô Liodoro, senhor das terras e dos buritis:

O Buriti Bom formava uma feição de palácio. Mesmo, naquele casarão de substante limpeza e riqueza, o viver parava em modos certos, - a gente concernia a um estado pronto, durável. Faltava uma dona; porque iô Liodoro, conquanto rijo fogoso e em saúde como autoridade, descria de se casar segunda vez (ROSA, 2001 p. 130).

Liodoro é chefe patriarcal, com moral, dotado de bons costumes. Perante a sociedade, não possui mácula, representando o papel do senhor que, após a viuvez, resguarda-se para a família. Contudo, à sombra da noite, carece de mulher, visto que é ainda homem forte, viril, como o Buriti-Grande, magistral, viçoso, imponente, vendo tudo, como um Deus. Liodoro tem sủas amantes, sai à noitinha e volta só de madrugada. Liodoro lança seu sêmen e conquista mulheres, como Dionéia, esposa legítima do inspetor, que era impotente e, tentando resolver o seu problema, fora buscar ervas perto do Buriti-Grande. Dionéia, fogosa, abre-se como as folhas do buriti para Liodoro, nascem os frutos. A outra amante é a mulata Alcinda, que tem "fome de homem". A visão de Gualberto Gaspar, que conta as histórias do “compadre" para Miguel, sobre Alcinda e sobre o próprio Iô Liodoro, é a de que:

[...] até no ela comer comida ou doce, o senhor toma a impressão que ela está fazendo coisas (...). Iô Liodoro, compadre meu, está certo, não diverjo. Há-de, ele é viúvo são, sai aos repentes por aí, feito cavalo inteiro em cata de éguas, cobra por sua natureza. Garanhão ganhante.... Dizem que isso desce de família, potência bem herdada (ROSA, 2001 p. 163).

No povoado, todos respeitam e admiram Iô Liodoro e, ao mesmo tempo, invejam-no. Gualberto constrói o compadre como um herói, forte, detentor de poder, tanto que lhe cede o Buriti-Grande, que ficava em suas terras. As terras de Gualberto não são boas como as de Liodoro nem ele é tão macho como o compadre. "Iô Liodoro, grande, era que ele não 


\section{S Linguagens}

mostrava de si senão a forma. Força cabida, como a de uma árvore" (ROSA, 2001, p. 176). Eis a visão, para o leitor, de Iô Liodoro, um homem forte: meio homem, meio Buriti-Grande.

A relação Liodoro-Buriti-Grande também é ressaltada por Ana Maria Machado, pois o radical "lio" significa liso, duro, assemelhando-se com o buriti. Também "liana" tem relação com a árvore. Ela está no seio da família, na identidade, no nome da matriarca:

[...] árvore porque ele é Maurício, como sua mãe, a vovó Maurícia dos gerais, figura quase mítica evocada pela família. Maurício como mouro, moreno que é, diferente de sua filha Glorinha, loirinha (...). Mas, sobretudo, Maurício como o Buriti, palmeira cujo nome científico é Mauritia vinifera (MACHADO, 2003, p. 123).

O nome completo da personagem é Liodoro Maurício Faleiros. Nota-se que o sobrenome "Faleiros" também se relaciona à árvore, já que se refere ao falo. O buriti é símbolo masculino, de dominação, ainda mais o Buriti-Grande, o maior e mais vistoso entre os buritizais: "Faleiros como falo, acentuando o valor do buriti como símbolo fálico e encarnação vegetal do sexo" (MACHADO, 2003, p. 123). Em várias passagens do conto, o Buriti-Grande e Liodoro, signos de dominação e imponência, mesclam-se, sendo que o buriti sai de pano de fundo ou de mera paisagem e torna-se parte integrante da narrativa: "o BuritiGrande - igual, sem rosto, podendo ser de pedra. Dominava o prado, o pasto, o Brejão, a mata negra à beira do rio, e sobrelevava, cerca, todo o buritizal" (ROSA, 2001, p. 180).

Liodoro representa, assim, o patriarcalismo, o machismo e o conservadorismo onde sertão e homem dominam. A família, nesse contexto tradicional, era comandada pelo homem/pai, detentor de poder sobre os seus dependentes. $\mathrm{O}$ homem era autoridade em termos sociais, econômicos e políticos. A mulher, portanto, vista como inferior, deveria ser submissa.

O fazendeiro tem duas filhas contrastantes: Maria da Glória e Maria Behú. A primeira pulsante, bonita, corada, o sexo aflorando; a outra, feia e assexuada. Maria Behú é "a feia sem nenhum singelo atrativo - era a que se vestia sempre de escuro, e as golas tão altas, e contudo com rendinhas, que ao queixo lhe chegavam" (ROSA, 2001, p. 221). É murcha, tanto que o narrador a vê sem forma, sem beleza, frustrada. É beata e vive às voltas com rezas, fator relacionado ao nome, pois beata vem de beatice, beatitude: "as claras vogais em que se abre beata então se fecham e se cortam no escuro e triste som de Behú" (MACHADO, 2003, p. 134), Behú, pela sonoridade, lembra urubu, pássaro negro e popularmente agoureiro. Também Behú relaciona-se ao nome das mulheres que, na Antiguidade, participavam das procissões de Linguagens \& Cidadania, v. 19, jan./dez., 2017. 


\section{Singuagens}

enterro, ou seja, associa-se à morte e à tristeza. Baseando-se em Bataille (2004), Behú corporifica o lado religioso. Talvez a reza seja um caminho para fugir do desejo, que, mesmo inconsciente, atormenta-a. "Na vida dos crentes e dos religiosos, cujos desequilíbrios não são raros, a sedução nem sempre tem o genital como objeto, mas o erótico" (BATAILLE, 2004, p. 362). Nesse caso, há uma negação do instinto sexual e a sedução é sublimada, através do fascínio pela transcendência, pelo divino. Maria Behú, por exemplo, associa o buriti, representação do fálico, a uma igreja.

Sua aspiração pela vida divina se traduz no desejo de morrer para si mesmo. (...) a morte, que o religioso desejou, torna-se para ele a vida divina. Ele se opusera a ordem genital, que tinha o sentido da vida, e reencontra a sedução sob um aspecto que tomou o sentido da morte (BATAILLE, 2004, p. 362).

Maria Behú realmente morre às voltas com a reza, toda de preto e coberta para não deixar transparecer o corpo, o sexo, alegoria do carnal e do profano. Por sua vez, sua irmã, Glória, é alegria, sorrisos e felicidade; é clara, luz e brilho; "Maria da Glória, que era dada e toda clara, que radiava" (ROSA, 2001, p. 192). Por isso, seu nome encarna a alegria: "Glória - Alegoria - Alegria” (MACHADO, 2003, p. 141). Ela, além do mais, transpira a sensualidade sertaneja, com "vestidos bem abertos, as mangas encurtadas" (ROSA, 2001, p. 221). A visão de Miguel é a de uma mulher pronta para o amor. Ele sente desejo pela moça e é correspondido: "Maria da Glória ela era cadeiruda e seiuda, com olhos brilhantes e pele boa e pernas grossas" / "Maria da Glória tinha encorpo, tinha gosto, tinha cheiro. Maria da Glória tinha suor e cuspe" (ROSA, 2001, p. 190).

Glorinha guarda muitas semelhanças com seu pai, "uma onçazinha; assim tirando às feições do pai, acentuados sulcos que vêm do nariz para os cantos da boca". (ROSA, 2001, p. 120) "Como pai dela, iô Liodoro, era supremo e senhor, como o crescer das árvores" (ROSA, 2001, p. 154) Em decorrência disso, Machado (2003, p. 143) aponta que "ela herdou a sensualidade e a intensidade vital de iô Liodoro". Da mesma forma que a árvore, Glória cresceu, desenvolveu-se e aflorou para o amor.

Como o buriti, que representa o símbolo de virilidade, por ser uma árvore que se mantém ereta através da irrigação da água, semelhante ao órgão reprodutor masculino, irrigado pelo sangue em situação de ereção, outros elementos do cenário - o monjolo e a noite - tornam-se peças principais. No começo de "Buriti", o monjolo representa um movimento Linguagens \& Cidadania, v. 19, jan./dez., 2017. 


\section{Singuagens}

cíclico. Movido à água, é usado para moer milho e descascar café e arroz. O monjolo range dia e noite, sendo parte integrante da sinfonia do Buriti Bom. No silêncio da noite, com seus sons ou vazios, o monjolo ritmava, seguindo as angústias de Lalinha, os desejos de Glória, as rezas de Behú, as sandices do Chefe Zequiel, insone, sem posses, vivendo no moinho, às margens da vida, capaz de ouvir, passivo e medroso, cada pedaço de noite.

Chefe Zequiel vê, na noite, o contraste: silêncio - barulho, tanto que "a noite entorna os barulhinhos todos num, que a gente amortece os ouvidos”. (ROSA, 2001, p. 157) Durante a noite, ele tem a ideia fixa de que um homem ou um espírito viria para assassiná-lo. A noite é tristeza, solidão e mistério:

O Chefe ouvia, ouvia tudo, condenado. Quem o inimigo era? Quem vinha? A noite traspassa de longe, e se pertence mais como o chão que na árvore, que uma barriga de cobra (...). Custoso de se conhecer, no som em sons: tu-tu...tut...Na noite escutada. - Diacho! (...). O mato abanado. - Zequiel, você foi ouvir, agora teme! Visonha vã, é quem vem, se acerca do moinho, para não existir. (...). O mau espírito da parte de Deus, que vem contra. Tudo o Chefe não sabe, amarrado no horror (ROSA, 2001, p. 154-155).

Zequiel acredita que ficando atento durante a noite ele conseguiria impedir que algum mal atingisse a fazenda. Ele tinha que ouvir o piu do joão-de-barro, que era o mensageiro de qualquer novidade. $\mathrm{O}$ temor que a personagem tem da noite pode ser interpretado como uma metáfora do medo da morte. A noite, sob outro viés, simboliza "o tempo das gestações, das germinações, das conspirações, que vão desabrochar em pleno dia como manifestação da vida" (CHEVALIER; GHEERBRANT, 1991, p. 640). Em vista disso, o chefe teme não só a morte, como também os instintos naturais ligados à sexualidade. Assim como Maria Behú, ele tenta negar a libido e o universo erótico da fazenda e dos que nela habitam.

Para Ana Maria Machado (2003), os sons do monjolo e da noite, ouvidos pelo Chefe Zequiel, articulam-se e formam palavras. No seu mundo fantástico, a noite fala, carrega mistérios. A noite tem ruídos que só ele ouve, como o movimento dos bichos, os gemidos, os uivos, o sexo e o gozo de Liodoro. O monjolo no seu ritmo, sempre rodando, rodando, vê as pessoas se transformarem: Glória se tornar mulher, Lalinha aflora para o desejo, quer ter Glória nos braços, quer senti-la mulher. O monjolo, dessa forma, é considerado um intérprete nato do sertão, assim como Zequiel. Este, a cada passo, vai tornando-se um fantasma, semelhante àqueles que via durante a noite: "emagrecia diante da gente, entre um começo e 


\section{Singuagens}

um fim de uma conversa" (ROSA, 2001, p. 265). A noite o empurra para trás, suga suas esperanças de chegar a ser gente.

A noite também se apresenta como forte componente da narrativa, sendo tão vigorosa, que se constitui uma personagem. Corresponsável por conflitos, pela modificação de cursos narrativos e das personagens, muitas vezes opera como ponto de partida para tensões e revelações. A lua tira o sono de Lalinha: "tomar da lua tira o sono, e fundo cansa o abusar de nostalgias. Noites dessas, ao recolher-se, Lalinha se revolvia em si, se sentia inquieta e alheia, dava às vezes de se levantar da cama, reacender o lampeão fumar”. (ROSA, 2001, p. 240-1) A lua hipnotizava a jovem, fazia suar, sentir calafrios, arder de desejo. Lua-Lala-Buriti-Grande, que, na narrativa rosiana, é retratado como: "palmeirão descomunado" (ROSA, 2001,p. 140), “(...) descomum. Desmesura (...) ele tinha umidades” (ROSA, 2001, p. 151), “(...) Teso, toroso" (ROSA, 2001, p. 151). "E os buritis - mar, mar. Todo um país de umidade, diverso, grato e enganoso, ali principiava" (ROSA, 2001, p. 166), "e, em noite clara, era espectral um só osso, um nervo, músculo (...). Sua beleza montava, magnificava. Marcava obstáculo: um tinha que parar ali, momentos que fosse, por império" (ROSA, 2001, p. 180-1).

$\mathrm{Na}$ segunda parte, Lala destaca-se, sendo apresentado o seu interior e os seus sentimentos, diante da vida na fazenda, de Glória e de Iô Liodoro. Acontece, nessa fase, com mais intensidade, o afloramento dos desejos de Maria da Glória, diante da ausência de Miguel. A personagem erotiza-se aos olhos de Lalinha. Wendel Santos aponta que "o valor de Miguel para a erotização de Maria da Glória é, portanto, fundamental; e, através de Maria da Glória, sua ação amorosa propõe um novo movimento em Lalinha (...) uma permissão para se desvelar" (SANTOS, 1978, p. 133). Há uma aproximação entre Maria da Glória e Lalinha, após a partida de Miguel, visto que segunda se torna conselheira da primeira. "O buriti sempre sucedido, sempre em carne" (ROSA, 2001, p. 181), enquanto Maria da Glória passeia pela fazenda, fica corada, alegre, pronta para dar-se. Ela ia até o Brejão-do-Umbigo, lá se extasiava como se já tivesse sido possuída, tanto que o lugar "dava cheiros. Dava febres" (ROSA, 2001, p. 181). Enfim, o lugar, as flores, a água e o ar "cheiram a úmido de amor feito" (ROSA, 2001, p. 181).

Após a partida de Miguel, Lalinha sente que Glória precisa dela, pois de "rija e brincalhã, que antes, impetuosa, quase um rapaz, agora enlanguescia nostálgica, uma pomba, e o arrulho" (ROSA, 2001, p. 200). O desejo de Miguel se incorpora em Lala, que passa a ver 


\section{S Linguagens}

a cunhada e amiga com outros olhos: "Gloria se expandia, audaz, naquela quadra de ufa pastoril, se levantava cedo, montava, saía ao campo, à vaqueira, lado a lado com o pai. Voltava excitada e contente, remolhada de muitos orvalhos, e corada - uma maçã” (ROSA, 2001, p. 249). Ou seja, Lalinha a via enquanto fruto proibido, pecaminoso, porém desejado.

As duas começam a passear, ir até o Buriti-Grande, rir, olhar-se. Como lembra Machado, o nome Leandra era pouco mencionado na fazenda, sendo guardado somente a ela, como sinal de identificação oficial. No entanto, Leandra, como nome, tem muita significação, uma vez que "guarda o radical simétrico, andrós, o homem, a masculinidade" (MACHADO, 2003, p. 154). Em vista disso, no próprio nome, há insinuações de homossexualidade ou bissexualidade. Lala, em várias passagens, mostra o seu interesse por Glorinha. Ela quer ser acariciada, tocada e amada pela amiga:

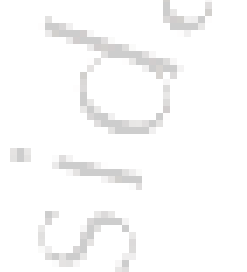

Pudesse, estaria deitada junto de Maria da Glória, queria que Maria da Glória, horas sem tempo, a abraçasse e beijasse, lhe desse todos os afagos, como se ela, Lalinha, Lala, fosse uma menina, um bichinho, diminuindo, cada vez mais diminuindo, até meio menos não existir, e dormir (ROSA, 2001, p. 214).

Glória também sente algo diferente, gosta da maciez das mãos e dos pés de Lala. Beija-os, e Lalinha deixa: "era bom, o bom calor das mãos moças palpando-lhe de leve o pé, sob o oculto das coberturas" (ROSA, 2001, p. 255). Freud (1969, p. 17-18) apresenta a pulsão como "uma representação psíquica das excitações, oriundas do interior do corpo e chegando ao psiquismo, como uma medida de exigência de trabalho que é imposta ao psíquico em consequência de sua ligação ao corporal". O conto se torna bastante transgressor quando trata do desejo das duas mulheres.

Com efeito, Corpo de baile quebra tabus ao abordar temas como a homossexualidade em "Buriti", os desejos reprimidos, castrados em "Campo geral", a sexualidade dos velhos em "Uma estória de amor", "A estória de Lélio e Lina", o ciúme doentio em "Dão-lalalão". Na maioria dos contos, os homens são machistas e veem as mulheres como pecadoras e desfrutáveis, havendo quase sempre a presença de prostitutas, vistas como mulheres do amor, ao contrário da figura da mãe, que personifica a imaculada e o lar. Nota-se, no entanto, que as narrativas avançam em direção a formar uma imagem da prostituta boa, como em "A estória de Lélio e Lina”, em que Conceição e Tomázia, além de servir às artes do amor, 
[...] criam galinha, também. Engordam até um porquinho...E plantam sua mandioquinha, também, e, entre a casa e as touceiras de bananeiras, tinham uma horta, condizida com sua cerquinha de varas (...). Havia também dois bancos, de talas de buriti. O Pernambuco brincava na viola; acocorado perto dele Placindo tocava seu berimbau. Peças de roupa secavam, numa corda, ou estendidas no capim (ROSA, 1994, p. 748).

O ambiente descrito é quase familiar. As duas prostitutas cuidam dos capiaus como seus filhos, matando seu desejo carnal e, literalmente, sua sede e sua fome. Outras, que também ganhavam a vida com o sexo, transformam-se em donas de casa, como Doralda. Ela deixa a vida de prostituição e mantém um relacionamento estável com Soropita. Doralda apresenta no nome a carga semântica de "durável, Doralda pássaro que se abre em vôo e dor (...). Doralda que se dá, sobretudo Doralda de odor e sensualismo" (MACHADO, 2003, p. 180). A sensualidade à flor da pele e o servilismo ao marido fazem parte do cotidiano de Doralda, abalando as estruturas machistas de Soropita.

O avanço maior, contudo, ocorre em "Buriti", pois Lalinha e Maria da Glória são moças de família e sentem prazer, não mais reservado somente às prostitutas. Lalinha revela seus desejos reprimidos: "Leandra (...) une-se de maneira diversa aos membros da família. É casada com Irvino. Relaciona-se sexualmente com Glória e com iô Liodoro" (MACHADO, 2003, p. 153). Assim, o contexto social do sertanejo, com conservadorismo, violência, contradições, sexualidade, está representado nas narrativas de Rosa.

A personagem Lala, moça citadina, vê os anos passarem no sertão. Sente-se sozinha, perdida, por não ser membro da família. Irvino sumira, tem um filho com a outra mulher, ou seja, nenhum laço a prende à família de Iô Liodoro. Nos natais, sente-se uma intrusa, ela “colheu um amargo. Talvez até sua presença, aquela noite, os desgostasse. Ela não era parente - o sangue, que deles, nela faltava. Como seria possível enanelar-se naquele círculo, forçar-se um lugar entre eles - uma família, um sêmen?" (ROSA, 2001, p. 238). O tédio toma conta do seu corpo, sente vontade de partir, de reconstruir a vida. Marca os meses, via o mudar dos dias, das estações, e não parte, está presa, enraizada, como o Buriti-Grande.

Ela gosta da noite, dos escuros. A noite a chama, como ao Chefe Zequiel, que pode ouvir os ruídos e "dissociar cada rumor, do que se passasse lá dentro da casa" (ROSA, 2001, p. 286). Talvez, de forma indireta, ele seja cúmplice dos desejos irrevelados de Lalinha. Durante a noite, a moça tem sonhos eróticos com Glória e, ao mesmo tempo, deseja Iô 


\section{S Linguagens}

Liodoro. Imagina Iô Liodoro "só ele, violando, por força e por dever, todas as moçinhas do arredor, iô Liodoro, fecundador majestoso" (ROSA, 2001, p. 278). Entre alucinações, provocadas pela noite e pelo isolamento na fazenda, Lala se vê com Iô Liodoro. A noite a transforma em loba, quer que Liodoro a veja, ache-a bonita e a deseje. Todas as noites, eles se procuram, falam, chamam-se com o olhar: "iô Liodoro é homem de pouco falar. A exceção vem justamente nos encontros com Lalinha, em que fala e falo se sobrepõem" (MACHADO, 2003, p. 128). Ela também provoca, pois se arruma, penteia-se, embeleza-se: "gostaria de poder certificar-se de todos os efeitos que sua sensível beleza produzia no semblante, no corpo dele, o macho" (ROSA, 2001, p. 274). Lalinha, prisioneira do sertão, já não dorme, seu corpo sua, excita-se e brota o desejo, Buriti-Grande. Assim, o narrador revela a atmosfera de erotismo, que havia no interior das personagens, isto é, o desejo de transgredir a interdição, através da consolidação de relações proibidas.

A vida no Buriti-Bom era calma, "um belo pôço parado. Ali nada podia acontecer, a não ser a lenda" (ROSA, 2001, p. 176), porém começa a transformar-se depois que Lalinha e Miguel vêm da cidade para o campo das gerais. Ambos têm um importante papel na aceleração do desejo de iniciação sexual de Maria da Glória. Miguel vê no rosto da jovem uma beleza virgem: "ela é ainda sadia, simples, ainda nem pecou, não começou" (ROSA, 2001, p. 124). O veterinário sente desejo, quer amá-la e iniciá-la sexualmente: "imagino Glorinha casada comigo, no mesmo quarto, na mesma cama" (ROSA, 2001, p. 124). Leandra sente o corpo comichar quanto sua pele toca a da amiga. Se há o desvelamento de Glória para o sexo, através das figuras masculinas Miguel e Gualberto e da feminina Lala, há, ao mesmo tempo, o retardamento da relação sexual de Lalinha e de Liodoro. Também não há a concretização do casamento entre Miguel e Glória, já que a narrativa termina com o veterinário passando pelo Buriti-Grande e aproximando-se da fazenda. $\mathrm{O}$ símbolo fálico continuava ali, dominando a fazenda.

Vale lembrar o signo do buriti, que, sob o ponto de vista de Wendel Santos (1978), antropomorfiza a natureza, através de duas dimensões: a do Buriti-Grande e a do Brejão-doUmbigo, que, de forma metafórica, representam o homem e a mulher. Se a imaginação material que preside a composição da imagem do Buriti-Grande se caracteriza pela dureza masculina, a imaginação material, que descreve a imagem do Brejão-do-Umbigo, caracterizase pela umidade feminina.

Linguagens \& Cidadania, v. 19, jan./dez., 2017. 


\section{S Linguagens}

O Buriti-Grande, símbolo fálico, adentra no brejão, vigoroso. O Buriti-Grande é o símbolo do órgão sexual masculino, e o Brejão-do-Umbigo, da excitabilidade e fecundidade feminina. Essa imagem é altamente erótica: é a relação sexual, a cópula e, por fim, o casamento, segundo Santos (1978) entre a terra e a água, gerando, muitas vezes, uma substância gelatinosa, de que o brejão é o representante:

O brejo não tinha plantas com espinhos. Só largas folhas empapadas, combebendo, como trapos, e longos caules que se permutam flores para o amor. Aqueles ramos afundados se ungindo dum muco, para não se maltratarem quando o movimento da água uns contra os outros esfregava (ROSA, 2001, p. 223).

O muco está na flora vaginal e, durante o ato sexual, favorece a penetração. Da união entre o Buriti-Grande e o Brejo nasce a vida. A água, que também representa vida e a continuidade, está presente, porque o terreno é pantanoso, vertendo água, onde brotam as plantas do amor e do ciclo da vida. O buriti permanece forte ano após ano, germinado. Também o monjolo permanece: ele que fazia parte da infância de Miguel, no início da obra, em "Campo geral", e que agora se fecha, em "Buriti”, batendo ritmicamente, sinal de que tudo continua e de que, na viagem, há uma ida e um retorno.

Portanto, o conto é interessante na medida em que mostra a sociedade do interior brasileiro com suas mazelas, desigualdades e contradições: poucos ricos e muitos pobres, sendo a metonímia do Brasil, desde a sua fundação até a atualidade. O conto é transgressor em relação à sociedade e à moral da época, sobretudo ao mostrar comportamentos e sentimentos no seu êxtase, na sua forma bruta, como o Buriti. Com a leitura de Buriti, o leitor conhece a sociedade patriarcal do interior, na verdade um interior universal, pois ele pode fazer um contraponto com a sua percepção de mundo. Pensando nisso podemos aproximar as considerações de Bakhtin (1988) ao postular que o homem elabora sua concepção de mundo, seu entendimento sobre si mesmo e sobre o outro a partir a linguagem, da palavra. Pode-se redimensionar para a sociedade que é inseparável da linguagem.

A partir da leitura, de Guimarães Rosa, por exemplo, o leitor pode repensar a sociedade, de forma mais crítica e emancipatória. A obra rosiana, além da oralidade, do falar simples do interior, há um trabalho apurado com a linguagem, há uma preocupação ética e estética, no qual relacionando o texto e contexto social estão em constante sintonia. Como o escritor mesmo dizia, em várias entrevistas, suas obras são: "simples tentativas de rodear e Linguagens \& Cidadania, v. 19, jan./dez., 2017. 


\section{Linguagens}

devassar um pouquinho o mistério cósmico, esta coisa movente, impossível, perturbante, rebelde a qualquer lógica, que é a chamada 'realidade', que é a gente mesmo, o mundo, a vida”. Guimarães Rosa deixou suas obras como um caminho para a apreensão da realidade, basta, nós, leitores sabermos utilizar as ferramentas e construirmos o nosso posicionamento não só sobre os problemas sociais e históricos, como também sobre nós mesmos, na construção da nossa identidade.

\section{REFERÊNCIAS}

BAKHTIN, M. Marxismo e filosofia da linguagem. 4.ed. Trad. Michel Laud e Yara Franteschi Vieira. São Paulo:HUCITEC, 1988.

BATAILlE, G. O erotismo. São Paulo: Arx, 2004.

BOURDIEU, P. A dominação masculina. 2.ed. Trad. Maria Helena Kühner. Rio de Janeiro: Bertrand Brasil, 2002.

CHEVALIER, J.; GHEERBRANT, A. Dicionário de símbolos. Rio de Janeiro: José Olympio, 1991.

FREUD. S. Pulsions et destins dês pulsions. In: Metapsychologie. Paris: Gallimard, 1969.

MACHADO, A. M. Recado do nome: leituras de Guimarães Rosa à luz do nome de seus personagens. 3.ed. Rio de Janeiro: Nova Fronteira, 2003.

ROSA, G. Noites do sertão. 9.ed. Rio de Janeiro: Nova Fronteira, 2001.

Ficção completa. Rio de Janeiro: Nova Aguilar, 1994. 2v.

SANTOS, J. C. F. Nomes de personagens em Guimarães Rosa. Rio de Janeiro: INL, 1971.

SANTOS, W. A construção do romance em Guimarães Rosa. São Paulo: Ática, 1978. 